\title{
INSIGHTS \\ Reflections on a career at the National Institutes of Health
}

\author{
Tonse N. K. Raju ${ }^{1}$ \\ Pediatric Research (2019) 86:408-410; https://doi.org/10.1038/s41390-019-0440-6
}

In 2002, after three decades in academic pediatrics, I applied for a position as Medical Officer at the Eunice Kennedy Shriver National Institute of Child Health and Human Development (NICHD). When asked during the interview about the reasons for my leaving the university, I said that I loved academia, but did not care for the 'three-to-four nights a month in-house calls' I was required to take, despite being an attending physician for decades.

NICHD offered the job and I took it.

However, I had no idea what Medical Officers did at the $\mathrm{NIH}$. 'They managed grants' - said an NICHD colleague. But what was there to manage a grant?

It did not take long for me to find out.

Until then, like for many others, the NIH remained a black-box for me, too. Being a principal investigator on one grant and a co-investigator on a few (a paltry success), I knew that NIH funded research grants. If your application receives a fundable score after the review, the NIH sends money to your university-similar to an ATM dispensing the requested cash after checking your password and account balance.

But I soon found out that NIH is not an ATM. The scientists at $\mathrm{NIH}$ are partners in science. As described below, they manage your funded grants and want you to succeed. When you do, they take pride in your success.

Medical Officers (physicians or surgeons) and Health Scientist Administrators (usually non-physicians with a Ph.D.) are considered Program Officials (PO). Each funded grant is managed by one PO.

The POs perform three basic functions. They are the portals linking the scientific community with $\mathrm{NIH}$. They help future grant applicants with the application process, including advising them about the best-fit agency for their proposals, recommending appropriate grant mechanisms, and advising strategies for crafting good applications. However, they are not allowed to 'write' an application for the applicant (although one person asked me to do just that, which I politely declined).

The POs manage the funded research grants. They review annual progress reports and approve continued funding. They process supplemental dollars requests; review and approve requests for changes in research design, institution, or study team members; and help resolving other technical issues. In some NIH institutes and centers, the POs will serve as Ex-Officio members in Data and Safety Monitoring Committee to provide the agency's perspectives, if requested by the committee.

The second function of the POs is to help advance the field of science. Because of their content expertise and interactions with the scientific community, they identify knowledge gaps and bring them to the attention of the agency leadership. If approved, they convene workshops and conferences and/or develop funding opportunity announcements (FOAs) to stimulate research in specific areas of science-thus, the POs are the spokesman for science.

The third and perhaps the most important responsibility of the POs is being the purveyors of taxpayer dollars. They ensure that all rules and regulations are followed impeccably, including a strict adherence to ethical conduct, avoiding real or apparent conflicts of interests, maintaining confidentiality, and assuring that the taxpayer dollars are spent with utmost efficiency to advance the $\mathrm{NIH}$ mission.

Each of the above three components of my duty guided my performance at NICHD.

Grantees often do not realize that the NIH grant awards are 'grants-in-aid,' not cost-reimbursements. The federal government awards funds (not all you asked for or needed) to conduct research, as if to say that it accepts the opinions of the peer review team that your work is important to advance public health, therefore as a token of support, they will send some taxpayer dollars to help you out. By contrast, contracts are tasks that the $\mathrm{NIH}$ requests you to perform-developing products (devices, websites), conducting surveys, or implementing Congressionally mandated programs (school immunizations). Therefore, the government pays the mutually agreed upon cost, including an allowable profit. All these are similar to the contract you might develop to have your house painted.

One of the most common questions I get asked from grant applicants is, 'how can I succeed in getting an NIH grant.' Success in securing a grant depends upon how strong is the proposal. There are no magic bullets to achieving this. But I have listed some generic points in Table 1 and provided additional suggestions below. I emphasize that these are my perspectives-for more comprehensive discussions, please refer to the sources provided in the citations. ${ }^{1,2}$

Two of the most important review criteria in a grant proposal are the significance and innovation. One must emphatically state the impact from one's research in advancing health, and highlight why the proposal is unique. Ask yourself: What is so great about this research of mine? What happens if I do not do this at all-who loses and who cares? If you can provide strong and convincing answers to these questions, you have conquered half the battle.

However, as medical historian I know that the long-term impact of many research studies may be difficult to anticipate. It took physicists centuries to realize the value of the discovery of gravitational forces, and decades to interpret the theory of relativity to explain time and space. But our discoveries are unlikely to belong in the same league as those of Galileo, Newton, and Einstein.

Three other review criteria are investigator(s), approach, and environment. Specify why you, and you alone, are the most qualified person to conduct the proposed research. Highlight your

\footnotetext{
${ }^{1}$ From the Department of Pediatrics, F. Edward Hébert School of Medicine, Uniformed Services University, 4301 Jones Bridge Rd, Bethesda, MD, USA
} Correspondence: Tonse N. K. Raju (rajutonse@outlook.com)

Received: 27 February 2019 Accepted: 21 March 2019

Published online: 26 May 2019 
Table 1. Suggestions for a Novice: how to succeed in securing NIH grants

Preparation

- Allow at least 3 months to develop a strong application.

- Read the FOA fully, be it the omnibus (generic) FOA, or a specific RFA (request for application) or PA (prgram announcement). Highlight the portions that may be unclear to you and discuss them with the PO.

- Send a draft of your proposal (one page) to the respective NIH entitie's PO and schedule a phone call.

- Do not contact multiple POs for the same application. Most POs know each other and contacts with multiple POs are wasteful. If you must do that for any reason, be sure that each of them knows who else has been contacted.

- Conduct a thorough literature review, and search the NIH Research Portfolio Online Reporting Tools website ${ }^{7}$ to see other NIH-funded studies related to your topic - underscore the differences between your proposal and those that were funded.

-When planning for a clinical trial, search Clinicaltrials.gov ${ }^{8}$ for similar trials, irrespective of funding, and country of research. Highlight the differences between your research and other trials. Also describe the value of your study to the collective knowledge base.

- Work with the university grants office while developing the budget.

- Be sure that the application is readable, aesthetically pleasing, and uncrowded.

- Enroll in grant writing courses, if offered by your institution.

- Have the application read by at least by three others: a colleague in your area of science, a friend outside your area of science, and a non-medical individual, preferably a college student with an English major. Request them to explain the research back to you, and ask them how many sentences they had to read more than once to understand-rewrite them all.

Submission and follow-up

- Plan on submitting your grant proposal through your institution 3 days before the due date, lest unforeseen issues lead to missing the deadline. The NIH does not extend due dates, except when natural disasters, such as earthquakes and severe weather issues occur in your area.

- If your paper gets accepted for publication after you submitted a grant proposal, work with the PO to see how this information can be conveyed to the study section.

- Post-submission materials also include new research awards and other recognitions, especially for training grant applications.

Resubmission

- Read the summary statement thoroughly, no matter the score. Underscore both the positive and negative comments.

- Contact the PO to discuss your responses prior to working on an amended application.

- Be polite in your response to previous critiques. Do not be argumentative; avoid displaying your anger or displeasure about negative comments. It is possible that comments you deem unfair may have elements of truth-recognize, acknowledge, and respond to them convincingly.

- Highlight the text containing your responses including new items, but do it sparingly. No use boldfacing an entire page.

After receiving the grant award

- Keep the PO copied on all correspondence with other NIH official on your grant.

- Inform the PO about major papers arising from your grant that get accepted for publication before they are published. This helps the NIH to be prepared to respond to the news media, if your publication is highlighted as a medical breakthrough story. The NIH also collaborates with you, your institution, and the journal to issue press releases ahead of time.

- Research advances arising from NIH-funded studies are important bits of information that help the NIH leadership when they testify in the U.S. Congress requesting appropriations for future years.

- Inform the PO on all major award you receive that result from NIH-funded research, except for a Lasker Award or a Nobel Prize-those the PO will come to know as soon as you do.

training, expertise and past experience, and underscore the strengths and uniqueness of available resources and support from your institution. Be sure that the methodology is sound. Identify potentials pitfalls and explain steps for their resolution.

For individual training grants (e.g., $\mathrm{K}$ grants), explain why you are the most qualified candidate to receive the award, and with such an award, how you plan on become an expert investigator in a specific area of science. Be specific about your career goals, which should match the proposed career development plan. Although superlatives may sound hollow, using them with justifiable evidence will convince the reviewers about their legitimacy. The reviewers must feel your passion about your desire for becoming an academician. Your mentors, too, should provide strong letters of support with as many specific details as possible-not simply say, 'heck of guy, we will hire him if he gets a K.'

Now, a few words about my tenure at NICHD.

I am highly gratified to see that many trainees and junior faculty I advised succeeded in receiving $\mathrm{NIH}$ grants, moved on to become independent investigators, and established themselves as respected academicians-a matter of great pride for all POs.
I am also pleased that some of my efforts to stimulate untapped fields of research in neonatal-perinatal medicine have succeeded. I authored or coauthored more than 20 FOAs and organized 24 workshops and conferences. These led to research in many critical neonatal/perinatal fields, some of which are: patient safety, neonatal resuscitation, periviable births, devices and instruments for neonatal/perinatal care, pregnancy in women with disabilities, postpartum allostatic load and their racial and ethnic disparities, and opioid use disorders.

Another highlight of my NICHD career was the 2005 workshop on near-term births. In this workshop I coined the phrase 'late preterm', and helped define it. It then becme part of the medical lexicon. The workshop executive summary ${ }^{3}$ led to the universal adaptation of the new phrase and to a disappearance of the word 'near-term.' The Centers for Disease Control and Prevention (CDC) began tracking annual statistics on late preterm births. Later, the CDC credited the impact of NICHD workshop as one of the many factors that helped dropping U.S. preterm birth rates, specifically, the iatrogenic late preterm births. ${ }^{4}$ The late preterm definition also led to further classification of term gestation. ${ }^{5}$ 
Finally, I will narrate a story about how the NIH became instrumental in helping me to launch my own research career, much before I knew what NIH was.

In the early 1970s, pursuing my 'MD-Pediatrics' post-doctoral degree from the University of Mumbai, I needed to write a thesis based on my research. Searching for a topic in our library journals, I stumbled upon a series of papers on atypical tuberculosis (TB), many of them by Dr. Lydia Edwards and her colleagues. ${ }^{6}$ Her team had described the epidemiology of atypical TB in the U.S., and its antigenic cross-reactivity with the standard TB skin tests. Reading these papers led me to wonder about the prevalence of atypical TB among the children with lymphadenitis I was seeing in my Mumbai hospital clinic. I thought it could be a good research project to fulfill my thesis requirement.

However, I did not have access to the atypical TB antigens. On an impulse, without informing my mentors, I sent a hand-written letter (I could not afford a typewriter) to Dr. Edwards using the address provided in the journal articles, requesting her to send atypical TB antigens for my studies in Indian children.

Months passed without a reply. I almost forgot about it, until one morning, about 3 months later, a box (from the USA, sent through the sea-mail) sat in front of my dorm door. It contained 100 vials with antigens, 25 vials for each of the 4 atypical TB bacterium, all preserved in ice. The accompanying letter thanked me for the request and noted that each vial could be used for 12 skin tests, allowing me to study a good number of children with lymphadenitis. The author of the letter wished me success. The letter was signed, 'Lydia Edwards, Ph.D., Chief of TB Research Division, National Institutes of Health, Bethesda.'

This led to my maiden research project on atypical TB using the antigens Dr. Edwards had sent. This was the first such study in India. The results were presented at the annual meeting of the Indian Association of Pediatric Surgeons in 1972. Thus, NIH had a major role in inaugurating my research career even before I had heard of $\mathrm{NIH}$.
More importantly, I was profoundly touched by Dr. Edward's gesture. With great kindness and utter sincerity, she had responded to a hand-written letter from a totally unknown student, tenthousand miles away. She knew the universal truth that diseases have no national boundaries. TB is TB, whether in Mumbai, Malawi, or Montenegro. The only way to advancing human health is through collective and collaborative research efforts.

The above anecdote also underscores the importance of being patient and perseverant in all of one's endeavors. I trust that some readers may find my story insightful.

\section{ADDITIONAL INFORMATION}

Competing interests: The author declares no competing interests.

Publisher's note: Springer Nature remains neutral with regard to jurisdictional claims in published maps and institutional affiliations.

\section{REFERENCES}

1. Center for Scientific Review. National Institutes of Health. Peer review related video. https://www.youtube.com/watch?v=fBDx|6|4dOA\&version=3\&hl=en_US. Accessed 18 Feb (2019).

2. 29th NICHD Young Investigators' Conference Proceedings and Presentations. https://www.nichd.nih.gov/about/meetings/mfneo-repro/default. Accessed 18 Feb (2019).

3. Raju, T. N. K., Higgins, R. D., Stark, S. A. \& Leveno, K. G. Optimizing care and outcome for late-preterm (near-term) infants: a summary of the workshop sponsored by the National Institute of Child Health and Human Development. Pediatrics 118, 1207-1214 (2006)

4. Raju, T. N. K. Late preterm births-ten years later. Pediatrics 139, 1-2 (2017).

5. Spong, C. Y. Defining "term" pregnancy: recommendations from the defining "term" pregnancy workgroup. JAMA 309, 2445-2446 (2013).

6. Edwards, L. B. et al. An atlas of sensitivity to tuberculin, PPD-B, and histoplasmin in the United States. Am. Rev. Respir. Dis. 99, Suppl:1-132 (1969).

7. National Institutes of Health. Research portfolio online reporting tools. https://report.nih.gov/. Accessed 2 Feb (2019).

8. Clinical Trials.Gov. https://clinicaltrials.gov/. Accessed 2 Feb (2019). 